\title{
Theoretical and Experimental Research on Switching Optimization of No. 9 Single Turnout with $60-\mathrm{kg} / \mathrm{m}$ Rails
}

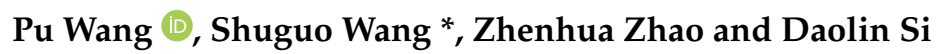 \\ China Academy of Railway Sciences CO., Ltd., Beijing 100081, China; wpwp2012@yeah.net (P.W.); \\ zhenhuazhao1980@163.com (Z.Z.); sidaolin@163.com (D.S.) \\ * Correspondence: zzddxx4473@sina.com
}

check for updates

Citation: Wang, P.; Wang, S.; Zhao,

Z.; Si, D. Theoretical and

Experimental Research on Switching Optimization of No. 9 Single Turnout with 60-kg/m Rails. Machines 2021, 9 , 294. https://doi.org/10.3390/ machines 9110294

Academic Editor: Fengming Li

Received: 8 October 2021

Accepted: 15 November 2021

Published: 19 November 2021

Publisher's Note: MDPI stays neutral with regard to jurisdictional claims in published maps and institutional affiliations.

\begin{abstract}
Based on the necessity of optimizing the structure of No. 9 single turnouts of $60-\mathrm{kg} / \mathrm{m}$ rails, we addressed the issues associated with existing turnout switching design methods. Based on finite element analysis, we established a refined calculation model for turnout switching. The model can determine the plane alignment of a switch rail separated from the stock rail based on the actual force acting upon the switch rail. The obtained plane alignment is consistent with the actual situation and is thus reliable. Based on the established turnout switching model, the minimum flangeway width and dynamics between the strokes of the first and second traction points under different conditions were analyzed by numerical simulations. Accordingly, we propose an optimized scheme that takes $160 \mathrm{~mm}$ and $85 \mathrm{~mm}$ as the stroke value for the first and second traction points, respectively. The scheme helps to meet the requirements for minimum flangeway width while making the deformation of the switch rail more even and therefore minimizing the traction power. Based on the proposed design, trial production and laying of the new No. 9 single turnout with a $60-\mathrm{kg} / \mathrm{m}$ rail was conducted, and a switching test was performed. The switching forces at the first and second traction points of the new No. 9 turnout were approximately 1200 and 2000 N, respectively, which were higher than those of existing No. 9 turnouts with $60-\mathrm{kg} / \mathrm{m}$ steel rails. Besides, the minimum flangeway width satisfies the requirement for safe vehicle passage with a safety margin of 3-5 mm. The test results proved the effectiveness of the proposed turnout switching design method and parameter optimization scheme.
\end{abstract}

Keywords: No. 9 single turnout; turnout switching calculation model; actual plane alignment of separated switch rail; traction point stroke optimization; turnout switching test

\section{Introduction}

In designing railway turnouts, the plane alignment of turnouts is first identified. In this process, the plane alignment usually has an accurate design when the stock and switch rails are in close contact, but the design is often simplified when the rails are separated [1-4]. Shen et al. [5,6] studied aspects of this, such as turnout plane alignment, structure, and speed-up dimensions. Liu et al. [7] combined recently developed mature technologies and designed a new No. 12 single turnout with $60-\mathrm{kg} / \mathrm{m}$ rails, with a speed in a straight direction of $200 \mathrm{~km} / \mathrm{h}$. It enhanced the plane alignment and dimensions, optimized the structure, strengthened the resilience and stability of components, and ensured interchangeability with existing speed-up turnouts. He et al. [8] used system integration design methods to establish a body of design theories for $250-\mathrm{km} / \mathrm{h}$ passenger-dedicated lines. They covered turnout dynamic strength, seamless turnout design, conversion calculations, and track stiffness design, which helped optimize the turnout plane alignment. They also developed a new fastener system and electrical and mechanical structures at the first traction point of nose rails and realized a reasonable setting and homogenization of track stiffness at turnout crossings. Gao et al. [9] used the longitudinal-transverse coupling model to conduct indepth research on the ballastless and jointless No. 42 turnouts to identify the longitudinal 
force and deformation, transverse deformation of turnout rails, the allowable temperature variation range of jointless turnouts, and the limiter's laying and maintenance methods. Cao et al. $[10,11]$ leveraged a plane parameter method to derive calculation formulas of various plane alignments, proposed a design process of the turnout plane alignment, and compared the application range and advantages and disadvantages of various alignments using actual calculation examples. Yang et al. [12] optimized the design of No. 9 single turnouts with $60-\mathrm{kg} / \mathrm{m}$ rails in subways. They adopted a straight-curve combined plane alignment, sliced the stock rail, and thickened the switch rail to increase the wear and impact resistance of switch rails. Guo et al. [13] elaborated on the design parameters and plane alignment of No. 62 turnouts, with a side allowable speed of $220 \mathrm{~km} / \mathrm{h}$, analyzed the switch, frog, fastener system, ballastless track foundation, switching system structure, and calculated principal component parameters. Furthermore, wheel-rail dynamics was used to analyze the safety and stability of Electric Multiple Units passing through No. 62 turnouts. Yang et al. [14] proposed the design principles and technical indicators applicable to No. 18 turnouts with $40 \mathrm{t}$ axle-load rails. The simulation analysis signified suitable dynamic performance of the plane alignment and fairly good wear resistance of the curved switch rails. To meet the construction needs of the Moscow-Kazan high-speed railway, Wang et al. [15] designed high-speed and wide-gauge turnouts suitable for $400 \mathrm{~km} / \mathrm{h}$. The design was based on dynamic analysis theory of high-speed turnouts and mostly covered plane alignment, profile processing of straight stock rails, vertically elevated structures of wing rails, and the stiffness of even and elastic turnouts. Luo et al. [16] researched the $160-\mathrm{km} / \mathrm{h}$ turnout system of urban rail transit lines, focusing on plane alignment, structure and construction, track foundations, and engineering-electrical interfaces. Wu [17] studied the No. 10 single turnout design with 1000-mm gauge and $50-\mathrm{kg} / \mathrm{m}$ rails and optimized and determined the plane dimensions of turnouts. Wu focused on the structure and engineering of the switch, frog, and track foundations and evaluated various parameters, such as the radius of the guide curve, the gauge widening, and the interval between various turnout parts.

Currently, the most commonly used method employs the following procedure: after designing the plane alignment of the switch rail in close contact with the stock rail is determined, the movable section of the switch rail is rotated with the fixed end or heel of the switch rail as the center of the circle until the displacement of the switch rail at the first traction point position is consistent with the designed stroke. The plane alignment, therefore, is considered as the plane alignment of the switch rail when not in a closed position. The plane alignment of the switch rail obtained in this way often remarkably deviates from the actual situation.

However, the plane alignment of the switch rail separated from the stock rail is important. For turnouts with internal locking, it is necessary to calculate and determine the lengths of the tie and connecting rods according to the plane alignment of the switch rail when separated from the stock rail. For speed-up and high-speed turnouts, the position of the components, such as the anti-jump iron block, is determined by the plane alignment of the switch rail when it is separated from the stock rail. In addition, the plane alignment determines the minimum width of the flangeway between the switch and stock rails, which directly impacts the design of the traction stroke. Therefore, the plane alignment of the switch rail in the separated state is measured as accurately as possible during the design. This simplified approach has major drawbacks: it can cause considerable deviations in the design of relevant components and the design of the traction stroke, resulting in a significant negative impact on the manufacturing, laying, and use of turnouts.

Currently, China's state-owned railways comprise about 22,000 sets of No.9 turnouts with $60-\mathrm{kg} / \mathrm{m}$ rails, representing a huge volume of railway laying. The No. 9 turnout is a $1 / 9$ turnout or a turnout with a crossing angle of arctan 1/9. The main product drawing number is CZ577, which was designed in 2002, and it is applicable to railway lines with a speed of $\leq 120 \mathrm{~km} / \mathrm{h}$ and a transverse passing speed of $35 \mathrm{~km} / \mathrm{h}$ [18-21]. Based on the on-site feedback and statistics, No. 9 turnouts of $60-\mathrm{kg} / \mathrm{m}$ rails are mainly used in the mainline, arrival, and departure line turnouts of the passenger and freight line I railways, 
arrival and departure line turnouts of heavy-haul railways, and other station line turnouts. There are prominent problems associated with the process, including poor maintenance of turnout geometric dimensions, short service life of components, and heavy maintenance workload [22-25]. There is an urgent need to boost the performance of No. 9 turnouts with $60-\mathrm{kg} / \mathrm{m}$ rails for railway engineering. Therefore, a study was organized by the China State Railway Group to improve the design of the main No. 9 turnouts with $60-\mathrm{kg} / \mathrm{m}$ rails $[26,27]$. Firstly, the dimensions of the new turnout were adopted consistent with those of previous turnouts to ensure interchangeability. Secondly, to address onsite issues and ensure safe dynamics of trains passing through the turnout, a series of new technologies was used in the new switch, such as straight-curve combined switch-rail technology to improve the wear resistance of the switch rail, the embedded iron seat fastener system to improve the switch's stability, and a new alloy-steel combined frog to increase the service life of the frog.

Based on optimization requirements and considering the shortcomings of existing design methods for turnout switching, herein, we revamped the switching design of the No. 9 single turnout with $60-\mathrm{kg} / \mathrm{m}$ rails, proposed a simulation calculation method to identify the plane alignment of the turnout switch rail in the separated state, and optimized key design parameters, including the traction point stroke and the length of the tie and connecting rods. Finally, the rationality of the design method and parameter scheme was verified through actual switching tests.

\section{Calculation Method for the Plane Alignment of Turnout Switch Rails Separated from Stock Rails}

The new No. 9 single turnout of $60-\mathrm{kg} / \mathrm{m}$ rails has the CZ577 turnout dimensions, with the total, front, and rear lengths of 29,569,13,839 and 15,730 mm, respectively. Considering the simplification-incurred change in the side rail gauge of turnout, the diverging rail takes R195-m single circular curve, the turnout Q value is $2600 \mathrm{~mm}$, and the gauge is widened to $1445 \mathrm{~mm}$ at the toe of the switch rail. The straight rail ends at the railhead slicing the starting point of the switch, and the end has a structural gauge widening by the curved stock rail deflection. The backtrack gauge is $1435 \mathrm{~mm}$, the lateral track gauge is maintained at $1445 \mathrm{~mm}$ and shifted back to $1435 \mathrm{~mm}$ before the turnout guard rail. The separation value of the diverging rail is $30 \mathrm{~mm}$, the length of the front straight section of the curved switch rail is $3499 \mathrm{~mm}$, and the width at the semitangent point is $54.9 \mathrm{~mm}$.

The switching adopts joint internal locking. The switch is designed with 2 traction points; the first traction point is $460 \mathrm{~mm}$ from the toe of the switch rail, and the second is $3625 \mathrm{~mm}$ from the first traction point and $5665 \mathrm{~mm}$ from the fixed end of the switch rail. The internal locking connecting rod is installed $1790 \mathrm{~mm}$ from the first traction point (Figure 1).

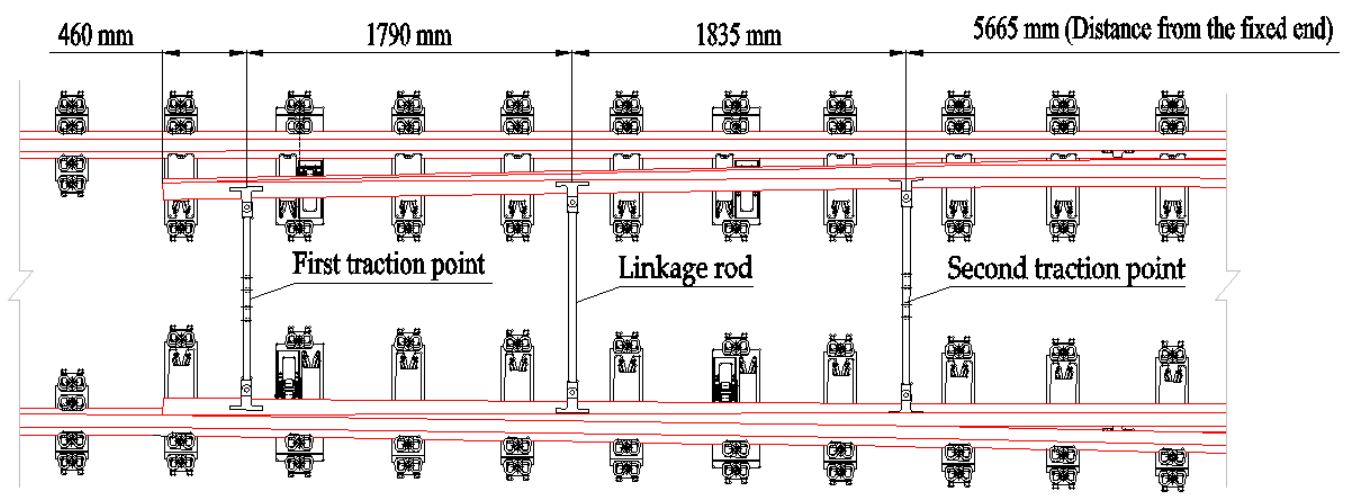

Figure 1. Design scheme for joint internal locking.

Existing CZ577 turnouts have been optimized in aspects such as the length of the switch rail and position of the traction point, and the switch rail adopts a more flexible 60AT2 steel rail. Therefore, existing stroke designs cannot meet the requirements regarding 
minimum flangeway width and other aspects, the stroke design at traction points is no longer adaptable. To ensure that the minimum flangeway width meets the requirement and minimizes the switching force, it is necessary to upgrade the design of the traction point stroke and length of the correspondent tie and connecting rods of internal locking.

The first step is to obtain the plane alignment of the switch rail that is not close to the stock rail by establishing a turnout switching calculation model based on finite element theory. It can serve as a rationale and means for the scientific design of the above parameters.

A solid unit is used to simulate the switch rail, with a material density of $7850 \mathrm{~kg} / \mathrm{m}^{3}$, modulus of elasticity of $2.1 \times 10^{11} \mathrm{~Pa}$, and Poisson's ratio of 0.3 [28-30]. The influence of the variable cross-section of the switch rail is considered, and each characteristic section of the switch rail is imported from the tip of the switch rail to the full cross-section, including the $0-\mathrm{mm}, 5-\mathrm{mm}, 20-\mathrm{mm}, 50-\mathrm{mm}$ and full sections of the top width of the switch rail, and the transition between the characteristic sections employs linear interpolation (Figure 2).

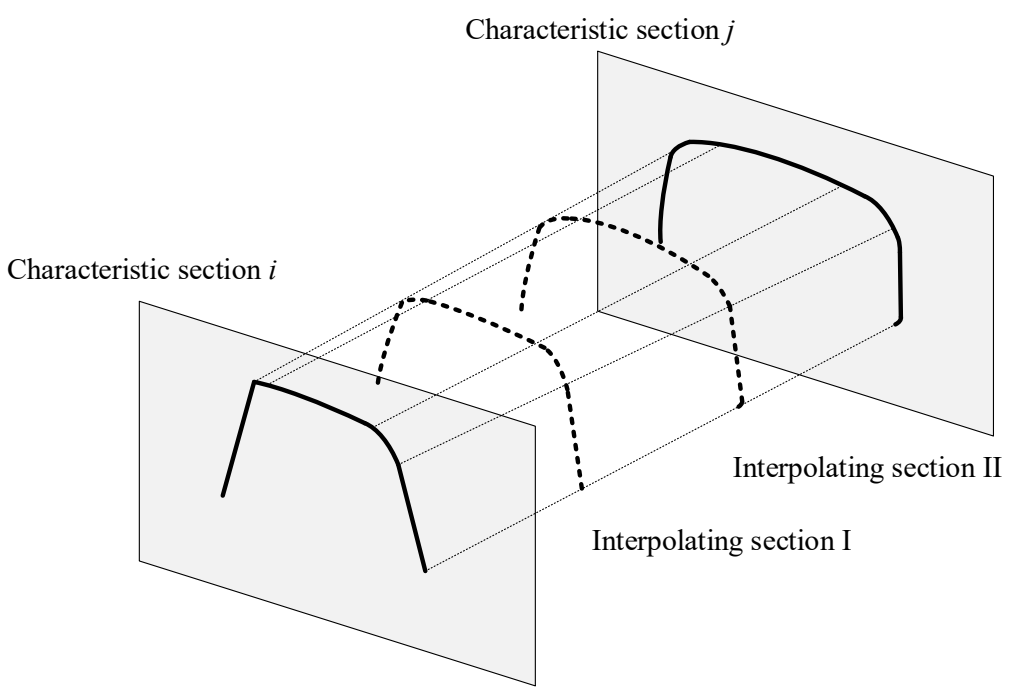

Figure 2. Transition between characteristic sections.

The heel of the switch rail is set as a fixed end support, and the influence of friction during the wrenching of the switch rail is considered. The spring unit is used to simulate the fastener system at the rear end of the switch rail. The lateral stiffness of the fastener system takes the values shown in Figure 3. The frictional force adopts a uniform load. The assumed weight of the switch rail is $70 \mathrm{~kg} / \mathrm{m}$, and the friction coefficient is 0.25 , so the applied frictional force is $175 \mathrm{~N} / \mathrm{m}$. When the switch rail is separated, transverse displacement load equal to the corresponding traction stroke is applied at each traction point. The switching simulation model is shown in Figure 4.

Through the above calculation, the transverse displacement distribution curve of the switch rail separated from the stock rail can be obtained (Figure 5), where $x$ is the coordinate of the longitudinal position along the switch rail, and $\Delta y$ is the transverse displacement of the switch rail at different positions. To facilitate subsequent analysis, the data are discretized. The switch rail is divided into $n$ segments along the longitudinal direction, resulting in $n+1$ nodes. The position coordinates of each node are $x_{1}, x_{2}, x_{3}, \ldots, x_{n+1}$, and the corresponding transverse displacement is $\Delta y\left(x_{1}\right), \Delta y\left(x_{2}\right), \Delta y\left(x_{3}\right), \ldots, \Delta y\left(x_{n+1}\right)$, respectively. 


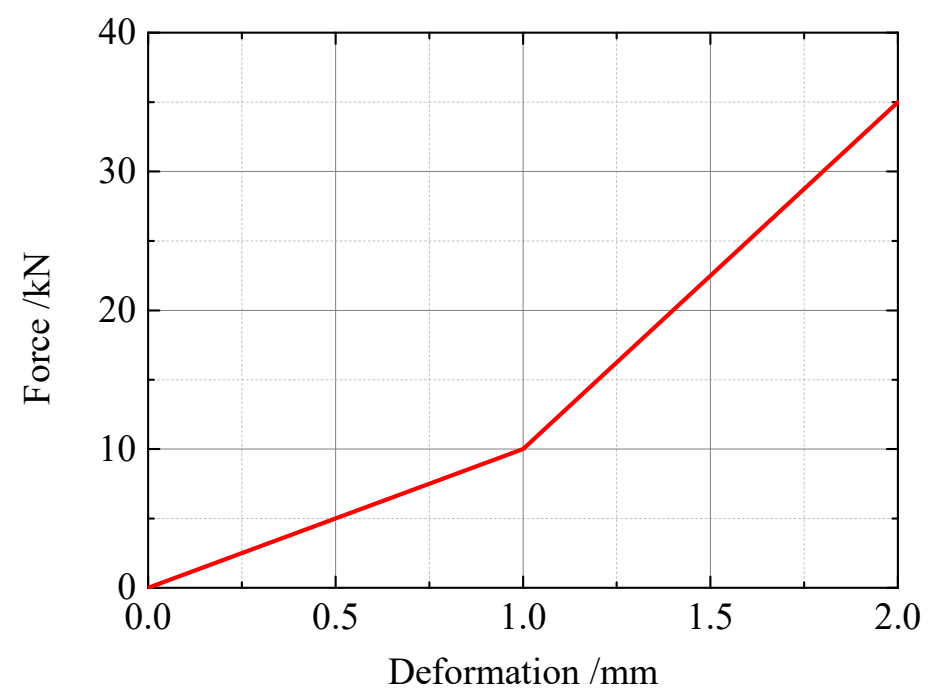

Figure 3. Transverse stiffness of fastener system.

Traction stroke 1

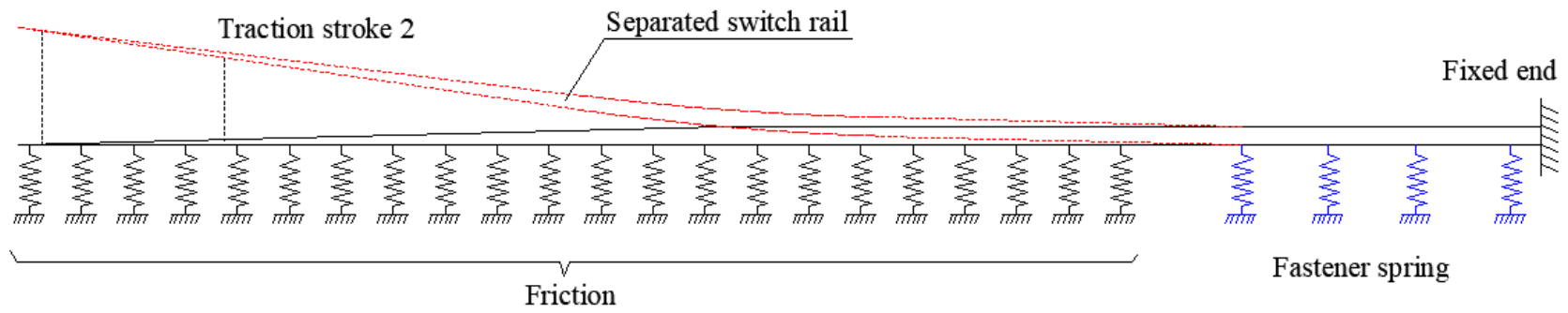

Figure 4. Turnout switching simulation model.

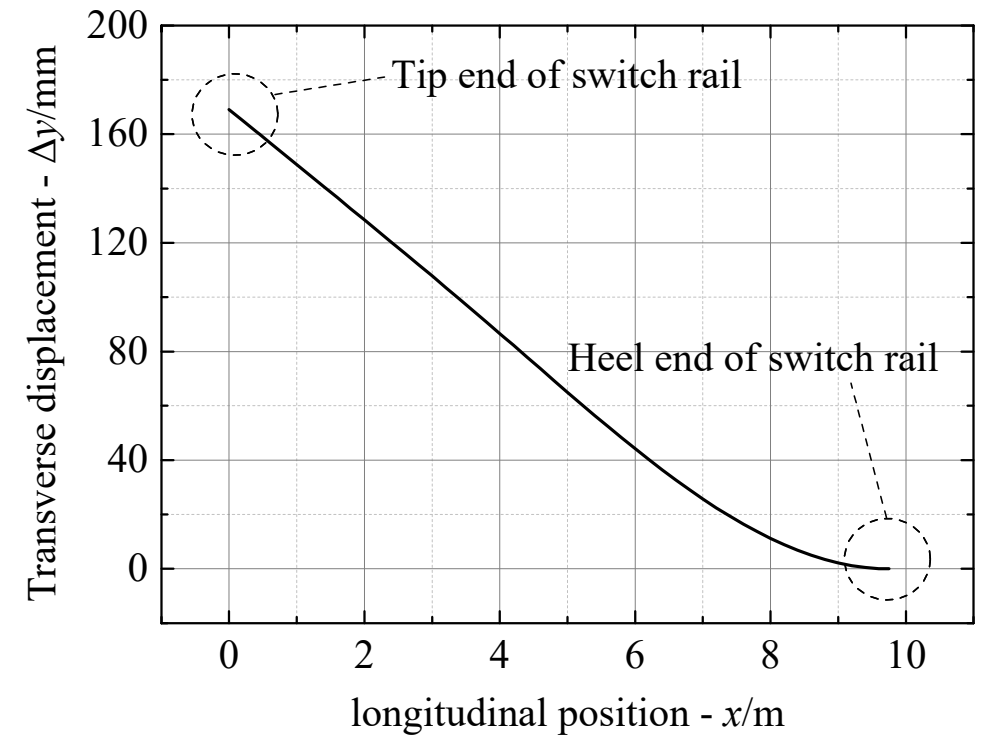

Figure 5. Transverse displacement distribution curve of switch rail separated from stock rail.

Based on the design scheme, the plane alignment of the switch rail very close to the stock rail is obtained. The same discretization method is employed on the switch rail to obtain the longitudinal position coordinates of $x_{1}, x_{2}, x_{3}, \ldots, x_{n+1}$ and the corresponding transverse position coordinates $y_{m}\left(x_{1}\right), y_{m}\left(x_{2}\right), y_{m}\left(x_{3}\right), \ldots, y_{m}\left(x_{n+1}\right)$. The transverse position coordinates $y_{m}\left(x_{i}\right)$ of the switch rail in contact with the stock rail and the displacement distance $\Delta y\left(x_{i}\right)$ after the separation from the stock rail are calculated by adding data on 
each discrete node $P_{i}(i=1,2,3, \ldots, n+1)$ to obtain the transverse position coordinates $y_{c}\left(x_{i}\right)$ of the switch rail when separated from the stock rail.

$$
y_{c}\left(x_{i}\right)=y_{m}\left(x_{i}\right)+\Delta y\left(x_{i}\right) \quad i=1,2,3, \ldots, n+1
$$

Based on the position coordinates $\left(x_{i}, y_{c}\left(x_{i}\right)\right)$ of each discrete node when the switch and stock rails are separated, the plane alignment $y_{c}(x)$ of the switch rail under the separated state can be obtained by sample curve fitting.

The stroke of the first traction point is preset to $160 \mathrm{~mm}$, and that of the second traction point is $75 \mathrm{~mm}$. Under this condition, the difference between the plane alignment of the switch rail under the separated state obtained using the proposed and traditional methods is shown in Figure 6. The transverse displacement of the switch rail under the separated state, obtained using the traditional method, is higher than that obtained using the proposed method; it is small only before the first traction point. The maximum deviation reaches $27.9 \mathrm{~mm}$, which is large enough to jeopardize the accuracy of the design of the parameters related to rail switching. In addition, the actual minimum flangeway width after assembly is less than $65 \mathrm{~mm}$ of the width of the flangeway is set at $65 \mathrm{~mm}$ during the design because the transverse displacement of the switch rail under the separated state obtained using the traditional method is larger than that in the actual situation. This adversely affects the safety of trains passing the turnout. The proposed method determines the plane alignment under the separated state based on the actual force imposed on the switch rail, which is consistent with the actual situation and more dependable.

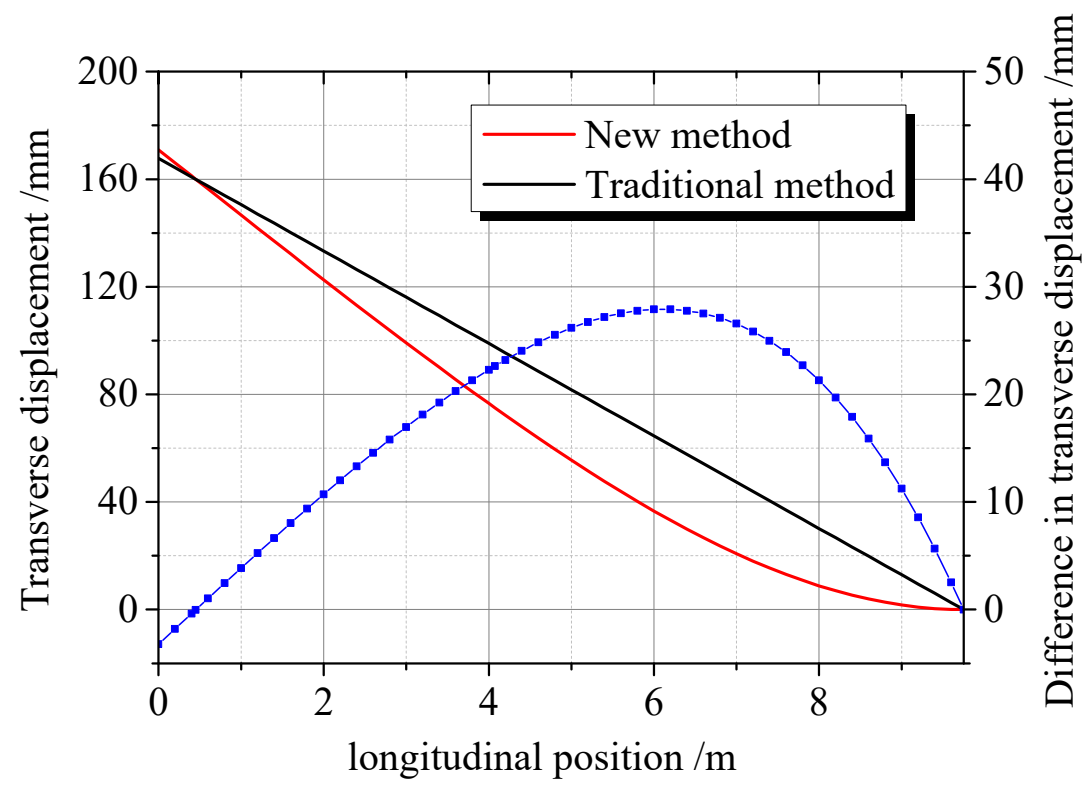

Figure 6. Difference in transverse displacement curves of switch rail under separated state.

\section{Optimized Design of the Traction Point Stroke}

Based on the developed turnout switching calculation model, the traction point stroke of the new-type No. 9 single turnout with $60-\mathrm{kg} / \mathrm{m}$ rails is optimized.

Firstly, considering the general design code for railway turnouts, the first traction point stroke is fixed to $160 \mathrm{~mm}$ [31-33]. The new No. 9 single turnout with $60-\mathrm{kg} / \mathrm{m}$ rails has 2 traction points, and the second traction point stroke needs to be properly designed. The design of the traction point stroke must meet the requirements of the minimum flangeway in the first place, i.e., the distance between the non-working edge of the switch rail and the working edge of the stock rail must be greater or equal to $65 \mathrm{~mm}$ in the switch rail when separated from the stock rail [34,35]. As the new No.9 single turnout with $60-\mathrm{kg} / \mathrm{m}$ rails slices the stock rail and thickens the switch rail to improve the wear resistance of the 
curved switch rail, and the working side of the straight stock rail is planned by $5 \mathrm{~mm}$, so the minimum flangeway width must be greater than or equal to $70 \mathrm{~mm}$.

The numerical test conditions are listed in Table 1.

Table 1. Numerical test conditions.

\begin{tabular}{cccc}
\hline Test Working Condition & First Traction Point Stroke & Second Traction Point Stroke & Notes \\
\hline 1 & $160 \mathrm{~mm}$ & $75 \mathrm{~mm}$ & CZ577 turnout design values \\
3 & $160 \mathrm{~mm}$ & $80 \mathrm{~mm}$ & \\
4 & $160 \mathrm{~mm}$ & $85 \mathrm{~mm}$ & \\
\hline
\end{tabular}

The transverse displacement curves of the switch rail when separated from the stock rail under different calculated working conditions are shown in Figure 7, and the results of the minimum flangeway calculation are listed in Table 2.

Table 2. Minimum flangeway width for different traction point stroke conditions.

\begin{tabular}{cccc}
\hline Condition $\mathbf{1}$ & Condition $\mathbf{2}$ & Condition $\mathbf{3}$ & Condition $\mathbf{4}$ \\
\hline $65.2 \mathrm{~mm}$ & $70.0 \mathrm{~mm}$ & $74.8 \mathrm{~mm}$ & $79.6 \mathrm{~mm}$ \\
\hline
\end{tabular}

When designing the traction stroke considering the No. 9 single turnout of $60-\mathrm{kg} / \mathrm{m}$ rails, the minimum flangeway width is $65.2 \mathrm{~mm}$, which does not meet the requirements and would affect the safe passage of trains through the turnout. With an increase in the stroke of the second traction point, the minimum flangeway width gradually increases. When the stroke of the second traction point reaches $80 \mathrm{~mm}$, the minimum flangeway is $70.0 \mathrm{~mm}$, a desired width, but with no safety margin, which does not meet the standard considering the influence of manufacturing tolerance. When the second traction point travels up to 85 and $90 \mathrm{~mm}$, the minimum flangeway width becomes 74.8 and $79.6 \mathrm{~mm}$, respectively, with adequate safety margins.

The design of the traction point stroke, besides minimizing the traction force at the first and second traction points, should reduce the working power of the switch device. In addition, the deformation of the switch rail should be coordinated to avoid uneven deformation. The additional numerical test conditions are set up as shown in Table 3 .

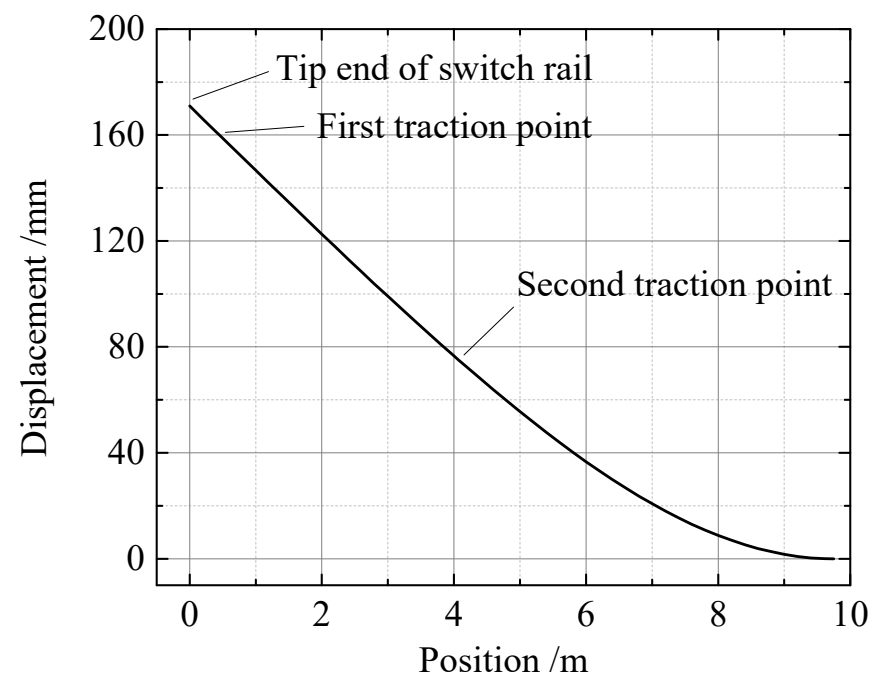

(a)

Figure 7. Cont. 


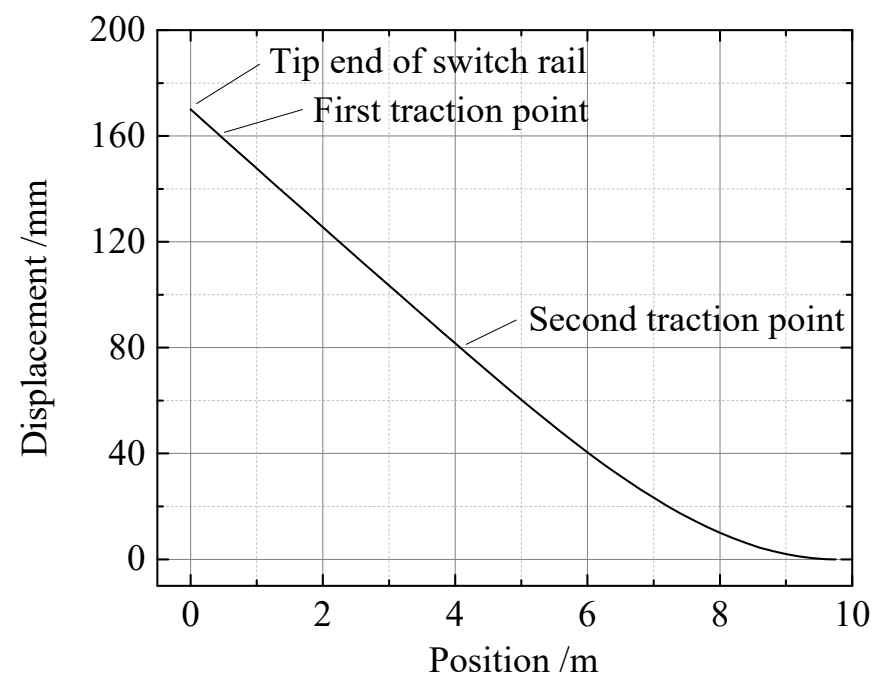

(b)

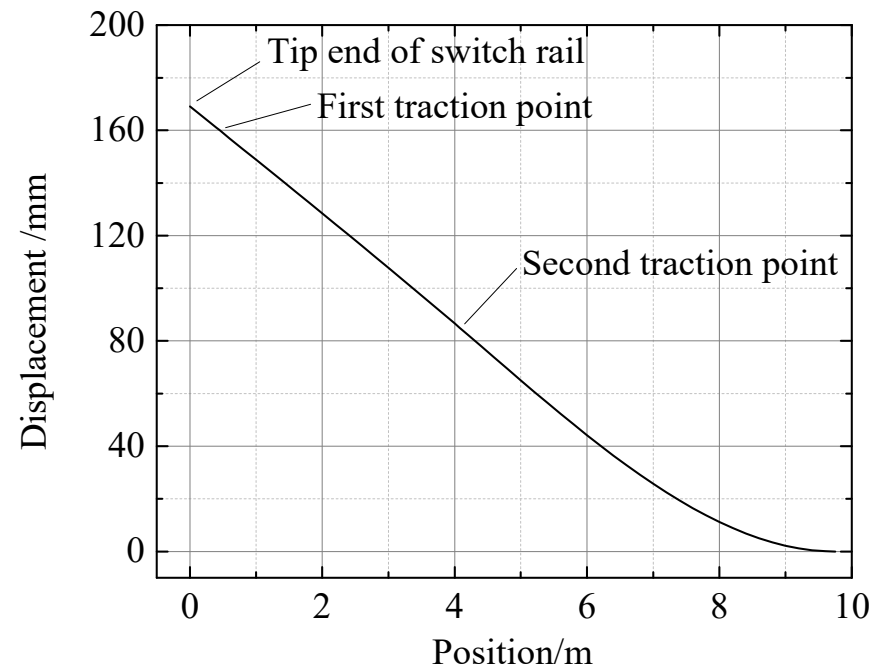

(c)

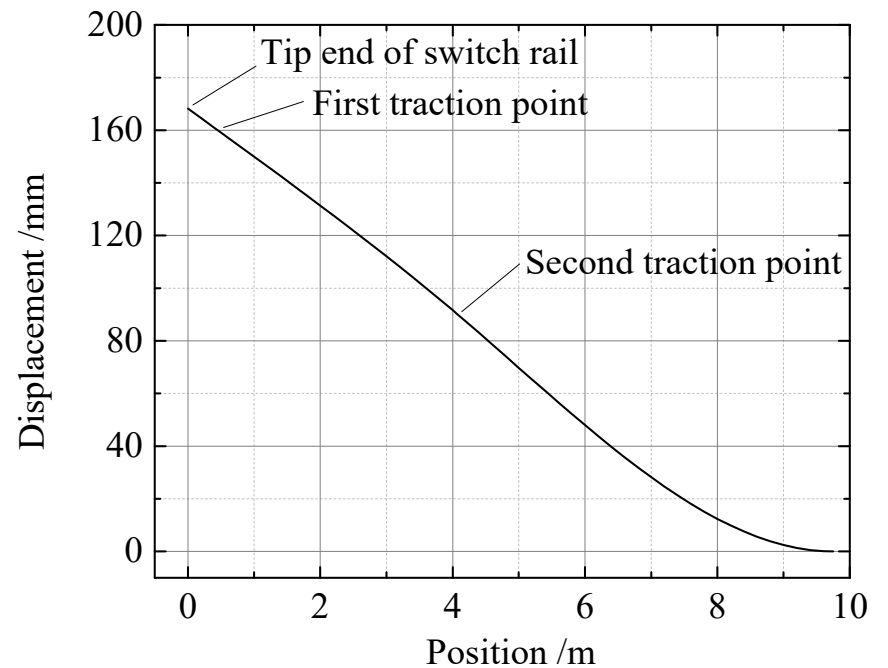

(d)

Figure 7. Transverse displacement curves of switch rail under separated state and different traction point stroke conditions. (a) Working condition 1, (b) Working condition 2, (c) Working condition 3, (d) Working condition 4 . 
Table 3. Numerical test conditions.

\begin{tabular}{ccc}
\hline Test Conditions & First Traction Point Stroke & Second Traction Point Stroke \\
\hline 5 & uncontrolled & $85 \mathrm{~mm}$ \\
6 & uncontrolled & $90 \mathrm{~mm}$ \\
\hline
\end{tabular}

The transverse displacement curves of the switch rail separated from the stock rail under different working conditions are shown in Figure 8, and the calculation results of the free stroke of the switch at the first traction point are listed in Table 4.

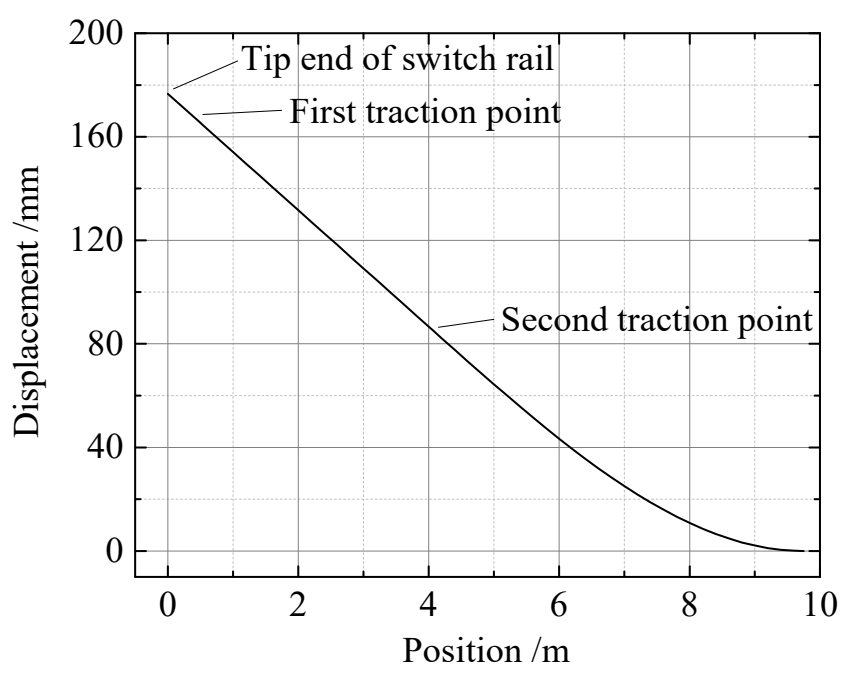

(a)

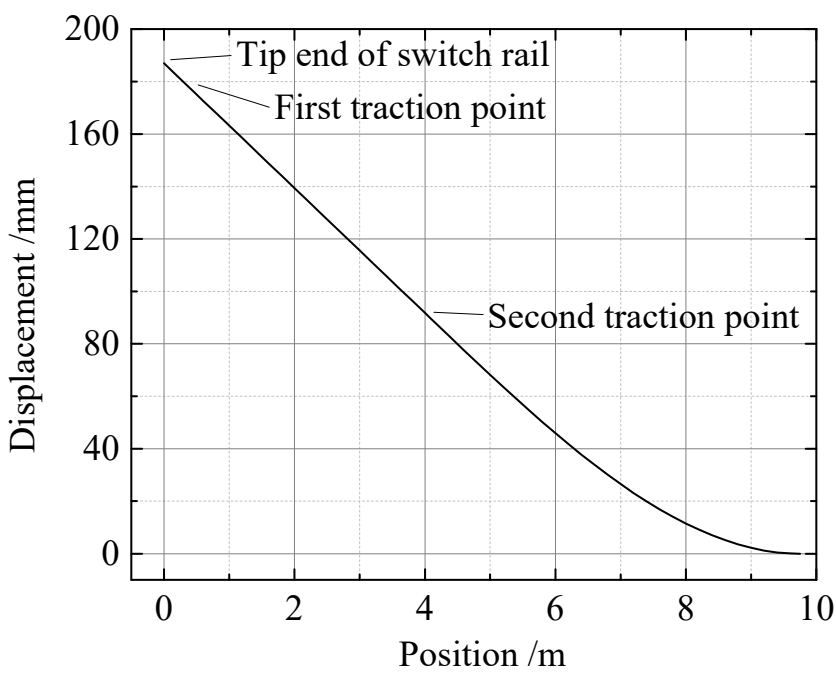

(b)

Figure 8. Transverse displacement curves of switch rail separated from stock rail under different stroke conditions at the second traction point. (a) Working condition 5, (b) Working condition 6.

Table 4. Free stroke for the first traction point under different stroke conditions at the second traction point.

\begin{tabular}{cc}
\hline Condition 5 & Condition $\mathbf{6}$ \\
\hline $166 \mathrm{~mm}$ & $176 \mathrm{~mm}$ \\
\hline
\end{tabular}

When the first traction point is released and the second traction point stroke is $85 \mathrm{~mm}$, the free stroke of the first traction point is $166 \mathrm{~mm}$. Therefore, when $160 \mathrm{~mm}$ of the stroke is applied to the first traction point, the switch rail is deformed in a more coordinated way, and the strokes of the first and second traction points match better. When the first traction point is released and the second traction point stroke is increased to $90 \mathrm{~mm}$, the traction force of the second traction point would be increased, and the free stroke of the first traction point reaches $176 \mathrm{~mm}$. Then, if $160 \mathrm{~mm}$ stroke is applied at the first traction point, the switch rail deformation becomes uneven, and the first traction point produces a reverse obstruction effect, further increasing the traction force of the second traction point.

In summary, the simulation shows that when the stroke of the second traction point is $85 \mathrm{~mm}$, the requirements of the minimum flangeway can be satisfied while leaving a safety margin. In this case, the deformation of the switch rail can be more even, the strokes of the first and second traction points match better, and the traction power is reduced to the minimum. Therefore, for the new No. 9 single turnout of $60-\mathrm{kg} / \mathrm{m}$ rail, the strokes of the first and second traction points are designed to be 160 and $85 \mathrm{~mm}$, respectively. 


\section{Switching Test Verification}

Based on the proposed design, the new No. 9 single turnout of $60-\mathrm{kg} / \mathrm{m}$ rail was constructed and laid (Figure 9).

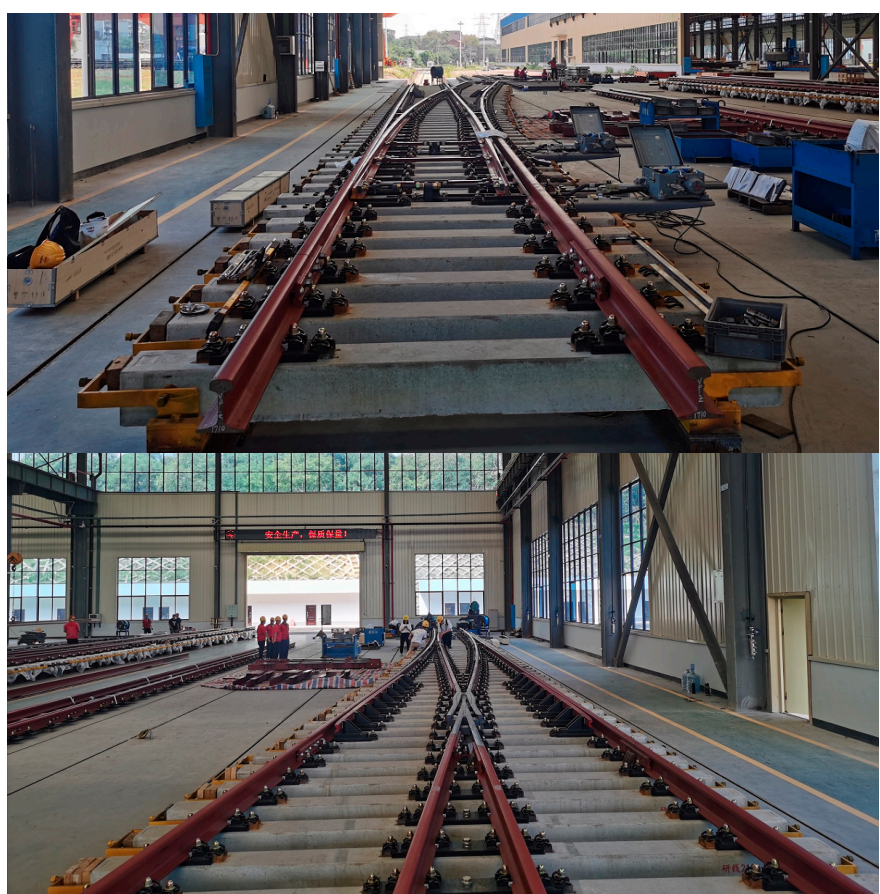

Figure 9. Laying of new No. 9 single turnout of $60-\mathrm{kg} / \mathrm{m}$ rail on manufacturing site.

A ZD6 electric switch and supporting locking devices were installed and conditioned at two traction points. After acceptance, a switching test was conducted. First, multiple cycles of pre-switching were conducted, and then, measurements and data reading were started.

Switching force was measured using a pin-type load cell (Figure 10). The measured signal was converted to data using a dynamic signal test analyzer and the data were analyzed and stored using DHDAS software. After measuring the switching force, a special caliper was used to gauge the minimum flangeway (Figure 11).

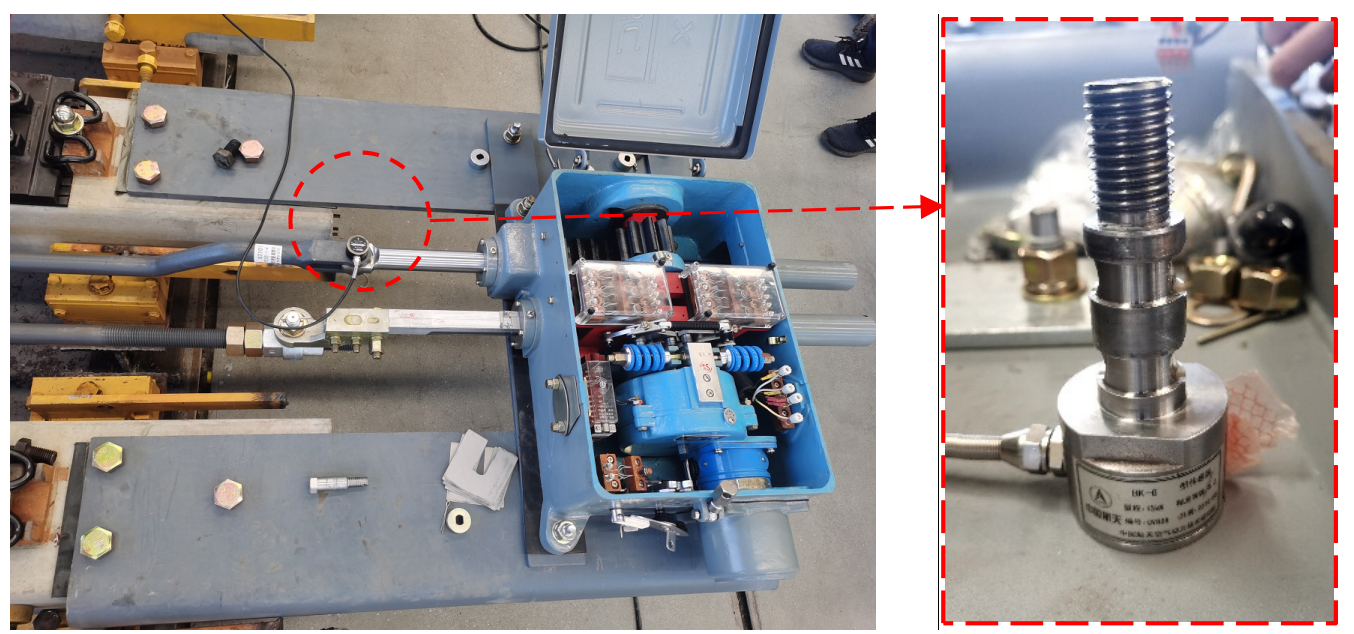

Figure 10. Switching force test. 


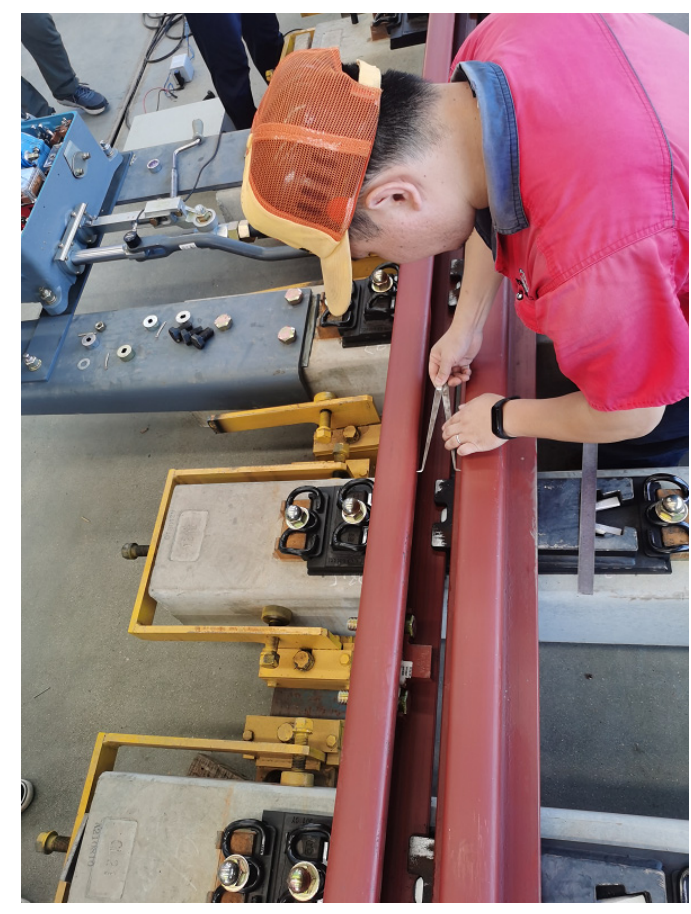

Figure 11. Minimum flangeway test.

After the pre-switching, the switch was flipped back and forth three times. The switching force at different traction points during each flip and the test result of the corresponding minimum flangeway after the flip are shown in Tables 5 and 6, respectively.

Table 5. Turnout switching force (N).

\begin{tabular}{cccccc}
\hline & & First Time & Second Time & Third Time & Average Value \\
\hline \multirow{2}{*}{ Forward $\rightarrow$ Inverted } & First traction point & 1400 & 1300 & 1500 & 1400 \\
& Second traction point & 1900 & 2200 & 2200 & 2100 \\
\hline \multirow{2}{*}{ Inverted $\rightarrow$ Forward } & First traction point & 1100 & 1100 & 1200 & 1133 \\
& Second traction point & 2000 & 1800 & 2000 & 1933 \\
\hline
\end{tabular}

Table 6. Minimum flangeway (mm).

\begin{tabular}{lcccc}
\hline & First Time & Second Time & Third Time & Average Value \\
\hline Straight switch rail under separation state (inverted) & 78.2 & 77.6 & 77.6 & 77.8 \\
Curved switch rail under separation state (forward) & 74.9 & 74.9 & 75 & 74.9 \\
\hline
\end{tabular}

The average switching force was 1400 and $2100 \mathrm{~N}$ at the first and second traction points, respectively, when pulled from the forward to the reverse position. When pulled from the reverse to the forward position, the force was 1133 and $1933 \mathrm{~N}$ at the first and second traction points, respectively.

The average value of the minimum flangeway in the straight switch rail when separated from the stock rail was $77.8 \mathrm{~mm}$ (because the side stock gauge was widened by $10 \mathrm{~mm}$, so it must be $75 \mathrm{~mm}$ or higher), with a $3.8-\mathrm{mm}$ safety margin. The average value of the minimum flangeway in the curved switch rail separated from the stock rail was $74.9 \mathrm{~mm}$ (because the straight stock rail was planned by $5 \mathrm{~mm}$, so it must be $70 \mathrm{~mm}$ or higher), with a 4.9-mm safety margin.

Based on the field test data, the switching force of the existing main-type No. 9 turnouts with $60-\mathrm{kg} / \mathrm{m}$ rail is $2000-3000 \mathrm{~N}$. In general, the new No. 9 single turnout with $60-\mathrm{kg} / \mathrm{m}$ rail exhibits a smaller switching force; thus, it is superior to existing main-type 
No. 9 turnouts. Besides, its minimum flangeway width meets the requirements and allows for a certain safety margin. The test data prove the effectiveness of the proposed switching design method.

\section{Conclusions}

In this study, based on the optimization requirements of No. 9 single turnout of $60-\mathrm{kg} / \mathrm{m}$ rail, we improved the switching design of No. 9 single turnout of $60-\mathrm{kg} / \mathrm{m}$ rail by removing the shortcomings of existing turnout switching design methods. Based on finite element theory, a turnout switching simulation method was established, which can determine the plane alignment of the switch rail based on the actual force acting upon it in the case where the switch and stock rails are separated. Hence, the obtained plane alignment is consistent with the actual situation and reliable. Based on this, we investigated the determination of reasonable stroke values of the traction point. Further, we analyzed the minimum flangeway width and the relationship between the stroke at the first and second traction points under different stroke conditions by numerical simulations. We further propose an optimization scheme or strokes of 160 and $85 \mathrm{~mm}$ for the first and second traction points, respectively.

Based on the proposed scheme, the production and laying of the new No. 9 single turnout of $60-\mathrm{kg} / \mathrm{m}$ rail, as well as the switching test, were conducted. The switching force of the new-type No. 9 turnout at the first and second traction points was approximately 1200 and $2000 \mathrm{~N}$, respectively, which are better than those of existing main-type No. 9 turnouts of $60-\mathrm{kg} / \mathrm{m}$ rails. The minimum flangeway also satisfies the requirements and has a safety margin of $3-5 \mathrm{~mm}$. The results prove the effectiveness of the proposed switching design method and parameter optimization scheme.

In further studies, the new-type No. 9 single turnout of $60 \mathrm{~kg} / \mathrm{m}$ rail, which is trialproduced, shall be laid on actual operating lines. In addition, long-term tracking and tests on the usage and switching status of the turnout will be conducted, and the design method and scheme will be further verified. In addition, the switch rail deforms as the temperature changes. However, such deformation will be insignificant for No. 9 turnouts because the overall turnout and switch-rail lengths are relatively short. Therefore, temperature variance was not factored into the switching design; instead, the analysis was performed under the middle value of onsite temperature ranges. In further studies, we will conduct a quantitative analysis of the impact of varying temperatures on the switching design. At last, the proposed approach will be applied and tested for other types and designation of turnouts.

Author Contributions: Conceptualization, P.W. and S.W.; methodology, P.W. and Z.Z.; software, P.W. and Z.Z.; validation, P.W. and D.S.; formal analysis, P.W.; investigation, P.W. and Z.Z.; resources, S.W.; writing —original draft preparation, P.W.; writing—review and editing, S.W.; funding acquisition, P.W. and S.W. All authors have read and agreed to the published version of the manuscript.

Funding: This research was funded by the National Natural Science Foundation of China, grant numbers 51808557 and51878661.

Data Availability Statement: Not applicable.

Acknowledgments: The authors appreciate the supports of CRSC Research \& Design Institute Group Corporation Limited, China Railway Shanhaiguan Bridge Group Corporation Limited, China Railway Baoji Bridge Group Corporation Limited, Turnout Branch Under China Railway Construction Heavy Industry Corporation Limited and CARS (Beijing) Railway Equipment Technology Corporation Limited for the construction and switching test of new turnout.

Conflicts of Interest: The authors declare no conflict of interest. 


\section{References}

1. Third Design Institute of Ministry of Railways. Design Manual of Turnout; People's Railway Publishing House: Beijing, China, 1975. (In Chinese)

2. Wang, P. Design of High-Speed Railway Turnouts Theory and Applications; Southwest Jiaotong University Press: Chengdu, China, 2016. (In Chinese)

3. Nielsen, J.C.O.; Palsson, B.A.; Torstensson, P.T. Switch panel design based on simulation of accumulated rail damage in a railway turnout. Wear 2016, 366-367, 241-248. [CrossRef]

4. Burgelman, N.; Li, Z.; Dollevoet, R. A new rolling contact method applied to conformal contact and the train-turnout interaction. Wear 2014, 321, 94-105. [CrossRef]

5. Shen, C.Y.; Wang, M.Z.; Xu, Y.Q.; Zhang, G.Y.; Wang, J.; Jiang, X.; Hou, A.B.; Tian, D.C.; Zang, A.L.; Gu, P.X.; et al. Design of plane and structure for speed-up turnout. Railw. Stand. Des. 1997, 3, 7-13.

6. Shen, C.Y. Development of $60 \mathrm{~kg} / \mathrm{m}$ Rail No.12 speed-up single turnout. Railw. Stand. Des. 1996, 40, 1-5.

7. Liu, H.; Yuan, B.J. Research and development of P60-12 type turnout with speed in straight direction of $200 \mathrm{~km} / \mathrm{h}$. Railw. Eng. 2006, 9, 72-73.

8. He, H. Research on the design theories and experiments of the $18 \#$ turnout under $250 \mathrm{~km} / \mathrm{h}$. J. China Railw. Soc. 2007, 29, 66-71.

9. Gao, L.; Qu, C.; Tao, K.; Qiao, S.L. Research on the design method of jointless switch no.42 on the ballastless track of passenger dedicated line. J. China Railw. Soc. 2011, 33, 76-82.

10. Cao, Y.; Wang, P.; Zhao, W.H. Study on turnout line-shape design based on plane parameters method. Railw. Eng. 2011, 2, 101-103.

11. Cao, Y.; Wang, P.; Yang, S. Dynamics study on turnout plane alignment selection. J. Huazhong Univ. Sci. Technol. 2017, 45, 35-40. (In Chinese)

12. Yang, L. Optimization design of metro no.9 single turnout using $60 \mathrm{~kg} / \mathrm{m}$ rail. Railw. Eng. 2021, 61, 149-154.

13. Guo, F.A.; Xu, Y.Q.; Xiao, J.H.; Wang, P.; Liu, Z.J.; Wang, S.G.; Sun, X.Y. Research on high-speed railway turnout with $220 \mathrm{~km} / \mathrm{h}$ speed in branch line. China Railw. 2012, 10, 8-12. (In Chinese)

14. Yang, D.S.; Qian, K.; Si, D.L. Design of no.18 turnout with 68 kg/m rail for $40 \mathrm{t}$ axle load. Railw. Eng. 2020, 60, 75-79.

15. Wang, P.; Xu, J.M.; Liu, D.Y.; Pang, L.; Yao, L. Key technologies of $400 \mathrm{~km} / \mathrm{h}$ broad gauge turnout design for high speed railway. High Speed Railw. Technol. 2019, 10, 14-22.

16. Luo, Y.; Qiao, S.L. Design of $60 \mathrm{~kg} / \mathrm{m}$ rail 12\# turnout used in Urban Rail Transit. Railw. Investig. Surv. 2020, 46, 142-146.

17. $\mathrm{Wu}, \mathrm{H}$. Research on the simple turnout design of meter-gage railway with no.10 and $50 \mathrm{~kg} / \mathrm{m}$ rail. Railw. Constr. Technol. 2017, 2, 13-17.

18. Wang, S.G.; Ge, J. Research Report on Railway Turnout Systematization and Structure Optimization of Main Turnout; China Academy of Railway Sciences: Beijing, China, 2020. (In Chinese)

19. Zhao, W.F.; Wu, X.S.; Zhang, X.Y.; Wang, S.G. Concise Manual of Railway Turnout Parameters; China Railway Publishing House: Beijing, China, 2019. (In Chinese)

20. China Railway Baoji Bridge Group Corporation Limited. Manual of Railway Turnout Parameters; China Railway Publishing House: Beijing, China, 2009. (In Chinese)

21. Sun, Y.Q.; Cole, C.; Boyd, P. A numerical method using VAMPIRE modelling for prediction of turnout curve wheel-rail wear. Wear 2011, 271, 482-491. [CrossRef]

22. Wang, S.G. Quality Analysis Report on Turnout of General Speed Railway; China Academy of Railway Sciences: Beijing, China, 2020. (In Chinese)

23. Wiest, M.; Kassa, E.; Daves, W.; Nielsen, J.C.O.; Ossberger, H. Assessment of methods for calculating contact pressure in wheel-rail/switch contact. Wear 2008, 265, 1439-1445. [CrossRef]

24. Wang, P.; Chen, R.; Xu, J.M.; Ma, X.C.; Wang, J. Theories and engineering practices of high-speed railway turnout system: Survey and review. J. Southwest Jiaotong Univ. 2016, 51, 357-372. (In Chinese)

25. Zhang, Z.F. Analysis of current situation of existing railway turnout and countermeasures of simplification and systematization. Railw. Eng. 2014, 54, 1-3.

26. Wang, S.G. Report on Improved Design Scheme of $60 \mathrm{~kg} / \mathrm{m}$ Rail No. 9 and No. 12 Main Turnouts; China Academy of Railway Sciences: Beijing, China, 2021. (In Chinese)

27. Wang, S.G. Safety Analysis Report of $60 \mathrm{~kg} / \mathrm{m}$ Rail No. 9 and No. 12 Turnouts of Passenger-Freight Railway; China Academy of Railway Sciences: Beijing, China, 2021. (In Chinese)

28. Cai, X.P.; Zhang, Q.; Wan, H.B.; Gao, Z.Z. Checking and Structure Optimization of Welded Turnout on 64 m-span Bridge in High Speed Railway. J. Railw. Eng. Soc. 2020, 37, 12-17.

29. Qiao, S.L.; Gao, L.; Qu, C.; Xin, T. Mechanical Properties of Continuous-Slab-Track Welded Turnout on Bridge. J. Southwest Jiaotong Univ. 2010, 45, 669-675. (In Chinese)

30. Xin, L.; Markine, V.L.; Shevtsov, I.Y. Numerical procedure for fatigue life prediction for railway turnout crossings using explicit finite element approach. Wear 2016, 366-367, 167-179. [CrossRef]

31. Zhao, Z.H.; Si, D.L.; Wang, P.; Wang, S.G. Design for New-type No.9 Simple Turnout of 50 kg/m Rail. China Railw. 2021, 7, 41-46. (In Chinese) 
32. Zhang, D.F. Design and Research on Heavy-Haul Railway Turnout for $75 \mathrm{~kg} / \mathrm{m}$ Rail with $30 \mathrm{t}$ Axle Load Used in Central and Southern Shanxi Railway. Railw. Stand. Des. 2014, 6, 17-22.

33. Eker, O.F.; Camci, F.; Guclu, A.; Yilboga, H.; Sevkli, M.; Baskan, S. A simple state-based prognostic model for railway turnout systems. IEEE Trans. Ind. Electron. 2011, 58, 1718-1726. [CrossRef]

34. Si, D.L.; Zhao, Z.H.; Wang, S.G.; Zhou, Y.F.; Hou, B.W.; Yang, D.S. Study on Switching Characteristics of Switch Rail for No.9 Turnout of New $50 \mathrm{~kg} \cdot \mathrm{m}^{-1}$ Rail. China Railw. Sci. 2021, 42, 27-33.

35. Sugiyama, H.; Sekiguchi, T.; Matsumura, R.; Yamashita, S.; Suda, Y. Wheel/rail contact dynamics in turnout negotiations with combined nodal and non-conformal contact approach. Multibody Syst. Dyn. 2012, 27, 55-74. [CrossRef] 